\title{
Validation of a Classification System for Obsessive-Compulsive and Related Disorders Based on DSM-5
}

\author{
Mehdi Rabiei', Vahid Donyavi2 ${ }^{*}$, Masoud Nikfarjam³, \\ Mohammad Ali Mohammad Nezhady4 \\ ${ }^{1}$ Department of Clinical Psychology, Baqiyatallah University of Medical Sciences, Tehran, Iran \\ ${ }^{2}$ Department of Psychiatry, AJA University of Medical Science, Tehran, Iran \\ ${ }^{3}$ Department of Psychiatry, Shahrekord University of Medical Science, Shahrekord, Iran \\ ${ }^{4}$ Young Researchers \& Elite Club, Urmia Branch, Isalamic Azad University, Urmia, Iran \\ Email: ${ }^{*}$ donyavi vahid@yahoo.com
}

Received 3 February 2015; accepted 1 March 2015; published 5 March 2015

Copyright (C) 2015 by authors and Scientific Research Publishing Inc.

This work is licensed under the Creative Commons Attribution International License (CC BY).

http://creativecommons.org/licenses/by/4.0/

(c) (i) Open Access

\begin{abstract}
The purpose of this study was to examine whether a broad obsessive-compulsive and related disorders model, which consisted of obsessive-compulsive, hoarding disorder, body dysmorphic, trichotillomania and pathological skin picking, displayed sufficient data fit. On the other hand, we examined whether a reduced obsessive-compulsive and related disorders symptoms model consisting of above mentioned disorders demonstrated superior fit or not. To test the factor structure validity of the classification system of obsessive-compulsive spectrum disorders, we used Confirmatory Factor Analyses (CFA). Result of factor structure analysis revealed and supported an OCSD symptoms dimension that included obsessive-compulsive, hoarding disorder, body dysmorphic, trichotillomania, and pathological skin picking symptoms. Also, results of this study supported the DSM-5 changes.
\end{abstract}

\section{Keywords}

Obsessive-Compulsive and Related Disorders, Obsessive-Compulsive Disorder, Factor Analysis, Validation

\section{Introduction}

The concept of an "obsessive-compulsive spectrum” of disorders has become popular currently. These condi"Corresponding author.

How to cite this paper: Rabiei, M., Donyavi, V., Nikfarjam, M. and Nezhady, M.A.M. (2015) Validation of a Classification System for Obsessive-Compulsive and Related Disorders Based on DSM-5. Open Journal of Psychiatry, 5, 137-143. 
tions are characterized as similar to obsessive-compulsive disorder in terms of phenomenology, associated features (age of onset, comorbidity, and clinical course), presumed etiology, familial transmission, and/or response to treatments [1]. The term "spectrum" has been used to mean many things; in this article, "OC spectrum" refers to a group of disorders that are presumed to be distinct from, but related to, obsessive-compulsive disorder (OCD), and which are characterized by repetitive thoughts and/or behaviors [2]. DSM-IV and DSM-IV-TR does not include a category of OC spectrum disorders (OCSDs). According to the American Psychiatric Association (APA), the publisher of the DSM-5, the major change for obsessive-compulsive disorder is the fact that it and related disorders now have their own chapter [3]. They are no longer considered as "anxiety disorders.” This is due to increasing research evidence demonstrates common threads running through a number of OCD-related disorders -obsessive thoughts and/or repetitive behaviors. The DSM-5 currently is going to consider grouping these disorders in a new diagnostic category: obsessive-compulsive and related disorders. This categorization would involve the inclusion of obsessive-compulsive, hoarding disorder, body dysmorphic, trichotillomania, and pathological skin picking [4]. Disorders grouped in this new class have features in common such as an obsessive preoccupation and repetitive behaviors. The disorders included in this new class have enough similarities to group them together in the same diagnostic classification, but they also have enough important differences among them to exist as distinct disorders.

The conference examined possible similarities in phenomenology, comorbidity, familial and genetic features, brain circuitry, and treatment response between obsessive-compulsive disorder (OCD) and several related disorders [5] [6]. Empirical corroboration has been growing for an OCSD symptom dimension that includes disorders with compulsive features (i.e., symptoms may reduce anxiety or prevent possible harm from occurring) even though it is unclear whether some impulse-control disorders or impulsivity symptoms warrant inclusion on this dimension [6]. Phillips et al. [7] believed that a category of OCSDs would increase the diagnostic validity and clinical utility of the classification system and from the perspective of clinical utility, there were advantages to grouping these disorders together, for the purposes of diagnosis and differential diagnosis, given similarities in their clinical features (obsessions/preoccupations and/or repetitive behaviors). The repetitive behaviors can involve complex compulsions or simple motoric behaviors, which are often associated with anxiety reduction and/or the regulation of arousal.

This study investigates the relationship between obsessive-compulsive, hoarding disorder, body dysmorphic, trichotillomania and pathological skin picking to exam the validity of classification systems for OCSD symptoms based on DSM-5. In addition, as the main aim of this study, we tested whether a broad OCSD model that included the above mentioned disorders displayed sufficient data fit.

\section{Methods}

\subsection{Participants}

Subjects were gathered in 2013. The Iranian sample consisted of 635 participants (304 male and 331 female) attending medical and psychology clinics of Isfahan city in Iran. In this study, sample size determined based on the expense of data collection and the need to have sufficient statistical power.

Exclusion criteria for all samples included presence of a neurological disorder, psychotic disorder, bipolar disorder, current substance dependence, acute suicidality or homicidality, and significant cognitive impairment. Participants ranged in age from 18 to 59 years old $(M=29.91$; S.D. $=6.57)$. Multi-stage cluster sampling method was used to select the samples. First "clustering" a total population by geographic region and next dividing each regional cluster into second-stage clusters by neighborhood, multi-stage sampling begins first with the construction of the clusters. Next, the investigator identifies which elements to sample from within the medical and psychology clinics, and so on until they are ready to survey. Participant's characteristics are presented in Table 1.

\subsection{Measures}

The measuring tools in this study were Massachusetts General Hospital Hair Pulling Scale, Skin Picking Impact Survey, OCI-R, and Yale-Brown Obsessive Compulsive Scale Modified for BDD.

\subsubsection{Massachusetts General Hospital Hair pulling Scale}

The Massachusetts General Hospital Hair Pulling Scale [8] is a 7-item self-report measure of hair pulling beha- 
Table 1. Participants characteristics $(n=635)$.

\begin{tabular}{|c|c|}
\hline Variable & \\
\hline Gender & n (\%) \\
\hline Women & $331(52.1)$ \\
\hline Men & $304(47.9)$ \\
\hline Age & yr (S.D.) \\
\hline Mean age & $29.91(6.57)$ \\
\hline Min-max & $18-59$ \\
\hline Occupational status & n (\%) \\
\hline Working full-time & 166(26.1) \\
\hline Student & 292(46.01) \\
\hline Part-time work & $70(11.01)$ \\
\hline Unemployed & $93(14.6)$ \\
\hline Retired & $14(2.2)$ \\
\hline Education & n (\%) \\
\hline Primary school & $90(14.2)$ \\
\hline High school & 406(63.9) \\
\hline University & 139(21.9) \\
\hline Psychotropic medication & n (\%) \\
\hline SSRI & $30(4.7)$ \\
\hline SNRI & $35(5.5)$ \\
\hline Benzodiazepines & $100(15.7)$ \\
\hline Antipsychotics & $15(2.3)$ \\
\hline Psychiatry disease duration & yr (S.D.) \\
\hline Mean length & $3(12)$ \\
\hline Min-max & $0-15$ \\
\hline
\end{tabular}

viors. The MGH-HPS evaluates the frequency, intensity, and control of hair pulling urges over a month. Items are rated on a five-point scale and composite scores ranging from 0 "no symptomology" to 28 "highly impaired." The MGH-HPS has been used in both clinical and non-clinical samples (Keuthen et al., 1995; Hajcak et al., 2006). Good internal consistency $(\alpha=0.89)$ [8] and test-retest reliability ( $r=0.97)$ [9] has been found for the MGH-HPS. Convergent validity support has been found with measures of trichotillomania, and convergent validity support for the MGH-HPS has been found with measures of depression, anxiety, OCI-R and Yale-Brown Obsessive Compulsive Scale Modified for BDD [9] [10].

\subsubsection{Skin Picking Impact Survey (SPIS)}

The SPIS [11] is a comprehensive survey covering a wide range of SPD related issues. The portion of the survey used in the current study included the questionnaires described below (i.e. SPS-R, DASS-21, \& SDS) and questions concerning time spent picking per day and the level of urge/arousal prior to picking. The Skin Picking Scale-Revised (SPS-R) is a self-report measure designed to assess the verity of SPD symptoms during the past week [12]. The original [13] contains six items covering the following domains: 1) frequency of urge to pick, 2) intensity of urge to pick, 3) time spent for picking, 4) interference due to skin picking, 5) distress due to picking/distress when prevented from picking, and 6) avoidant behavior due to picking. Convergent validity support has been found with measures of Skin Picking and convergent validity support for the (SPIS) has been found with measures of OCI-R and Yale-Brown Obsessive Compulsive Scale Modified for BDD [14].

\subsubsection{Yale-Brown Obsessive Compulsive Scale Modified for Body Dysmorphic Disorder}

BDD-YBOCS [15] is a reliable and valid 12-item semi-structured clinician administered instrument that evaluates current BDD severity. It is made to assess BDD-related preoccupations, repetitive behaviors, insight, and avoidance [3]. The reliability and validity of the BDD-YBOCS Persian translation version was demonstrated by Rabiei, Khoramdel, Kalantari \& Molavi [16] in both normal and clinical samples. They have shown that alpha 
coefficients ranged from 0.78 to 0.93 for the BDD-YBOCS total score and for its subscales (preoccupations, repetitive behaviors).

\subsubsection{Obsession Compulsion Inventory-Revised (OCI-R)}

The OCI-R [17] is an 18-item self-report questionnaire that rates obsessive-compulsive symptoms. The OCI-R is based on the earlier 84-item OCI [17]. Participants rate the degree to which they are bothered or distressed by OCD symptoms in the past month on a 5-point scale from 0 (not at all) to 5 (extremely). The OCI-R rates OCD symptoms across six factors: 1) washing, 2) checking, 3) obsessions, 4) mental neutralizing, 5) ordering, and 6) hoarding. Each of these subscales includes three scale items. The psychometric properties of the OCI-R are described above with a total score ranging from 0 to 72 and subscale scores ranging from 0 to 12 [17].

\subsection{Data Analysis}

To test the factor structure validity of the classification system of obsessive-compulsive spectrum disorders, the authors used Confirmatory Factor Analyses (CFA). To perform the analyses, the Structural Equation Modeling program AMOS 5 was used [18]. Values of the Goodness of Fit Index (GFI) and the Adjusted Goodness of Fit Index (AGFI) close to 1 represent a good fit, values of the Root Mean Square Residual (RMR) and Standardized Root Mean Square Residual (SRMR) below 0.05 represent a good fit, and values less than 0.08 represents an acceptable fit [18].

This investigation was approved by the local Ethics Committee in University of Isfahan, Iran.

\section{Results}

Means, standard deviations, minimum/maximum and the demographic characteristics of participants are reported in Table 1.

A broad OCSD symptom model including obsessive-compulsive, hoarding disorder, body dysmorphic, trichotillomania, and pathological skin picking demonstrated good to marginal data fit as evidenced by goodness of fit indices and factor loadings. The chi-square fit index was not significant, $\chi^{2}(35)=36.71, \mathrm{P}>0.05$, and RMSEA, RMR, GFI, CFI, and TLI values were 0.007, 0.04, 0.89, 0.91 and 99 respectively. Brown's (2006) recommendations of RMSEA close to 0.06 or less; CFI close to 0.9 or greater; TLI close to 0.95 or greater, and $\mathrm{P}>0.05$ demonstrated that the model had overall fit to the data. There are multiple limitations to the model chi-square (e.g., it is dependent on sample size and will almost always be significant with large samples) [18].

Thus, the reduced OCSD model that included obsessive-compulsive, hoarding disorder, body dysmorphic, compulsive hair pulling, and pathological skin picking symptoms demonstrated superior fit over the broad model (see Figure 1 and Table 2).

The factor structure of the classification system of obsessive-compulsive and related disorders was examined by means of CFA. Findings, reported in Figure 1 and Table 2, demonstrated that the model had overall fit to the data. As presented in graphs, the model had the best fit to the data and was closely related to the theo-

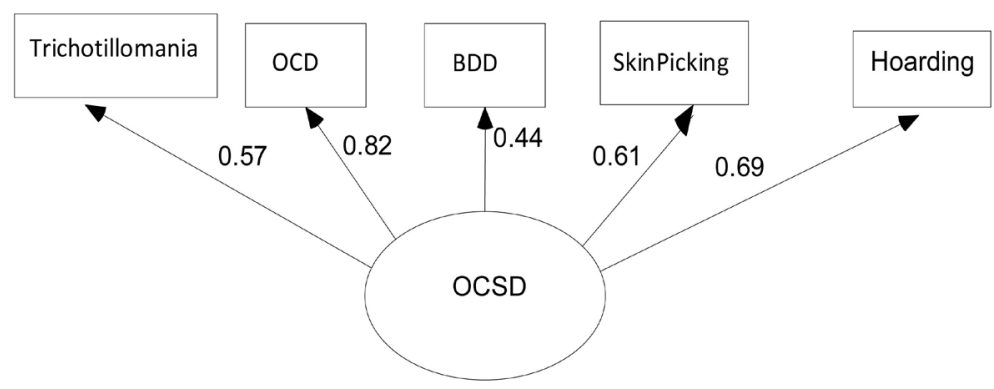

Figure 1. The factor structure of the classification system of Obsessive-Compulsive and Related Disorders. Note: Skin Picking = Skin Picking Scale-Revised (SPS-R); Trichotillomania = Massachusetts General Hospital Hair Pulling Scale; Hoarding and OCD = Obsessive-Compulsive Inventory-Revised; BDD = Yale-Brown Obsessive Compulsive Scale Modified for Body Dysmorphic Disorder. 
Table 2. "Model fit indices" for the model of the classification system of obsessive-compulsive spectrum disorders.

\begin{tabular}{cccccc}
\hline Model & N & GFI & AGFI & RMR & RMSEA \\
\hline & 635 & 0.90 & 0.89 & 0.04 & 0.007 \\
\hline
\end{tabular}

Note: N: number of participants; GFI: Goodness of Fit Index; AGFI: Adjusted Goodness of Fit Index; RMR: Root Mean Square Residual; RMSEA: Standardized Root Mean Square Residual.

retical assumptions of the classification system of obsessive-compulsive and related disorders.

\section{Discussion}

The current study examined the validity of the classification system of obsessive-compulsive and related disorders. The purpose of this study was to examine whether a broad obsessive-compulsive and related disorders model, which consisted of obsessive-compulsive, hoarding disorder, body dysmorphic, trichotillomania and pathological skin picking, displayed sufficient data fit.

Results from the present study indicate that the classification system of obsessive-compulsive and related disorders has sufficient data fit. The model (classification system) showed an acceptable fit in the sample. This confirms the construct validity of the measure and the underlying assumption of distinct symptom dimensions/subtypes belonging to category classification system of obsessive-compulsive spectrum disorders. Findings of this study revealed that the proposed version of the classification system of obsessive-compulsive spectrum disorders had a clear six-factor structure, congruent with its theoretical conceptualization (see Figure 1 and Table 2). Results of this study support the DSM-5 changes. Moreover, this is congruent with the results of Bartz and Hollander and Ettelt et al. [5]; Bartz and Hollander [19]; Sulkowski et al. [6]; Phillips et al. [7]. The findings, however, are not congruent with the results of [20]-[23].

The authors conclude that a number of disorders discussed in this study appear more closely related to OCD than to other neighboring disorders, and that there is merit to including an "OC spectrum group" of disorders in DSM-5. This conclusion is based on following perspectives: phenomenology, associated features (age of onset, comorbidity, and clinical course), presumed etiology, familial transmission, and/or response to selective treatments, clinical utility, face validity, and evidence from various validators. In summary, the results of this study support an OCSD dimension that includes obsessive-compulsive, hoarding disorder, body dysmorphic, trichotillomania and pathological skin picking. Thus, this study is more positive about the value of the new category of OCSDs in DSM-5.

There are also limitations in the study, meaning that the results need to be interpreted with some caution. The use of a non-clinical sample may limit the generalizability of these findings to clinical populations as well as to populations that are diverse in age, socioeconomic status, and other demographic variables. The use of a nonclinical sample also might be resulted to inflation of the associations among latent variables due to floor effects that could result from low levels of symptomology in most participants. Also, this study tested only one OCSD spectrums. Other spectrums containing tic disorders, addictions, autism, mood (e.g., depression) and anxiety symptoms have also been proposed due to the high co-occurrence of these symptoms with OCD. Future research is needed to test the narrow OCSD spectrum against competing spectrums. Ultimately, only self-report measures were included for each construct. Future studies may help these findings to be improved through using multiple measures of each construct and using different response formats (e.g., clinician-rated, self-report, interview).

Despite these limitations, altogether, it can be concluded that the DSM- 5 changes about the classification system of obsessive-compulsive spectrum disorders will increase the diagnostic validity and clinical utility of the classification system.

\section{Acknowledgements}

The authors would also like to acknowledge the assistance of participants and all of the clinicians and research assistants who conduct the assessments.

\section{Declaration of Conflicting Interests}

The author declared no potential conflicts of interest with respect to the research, authorship, and/or publication of this article. 


\section{References}

[1] Hollander, E. and Benzaquen, S.D. (1997) The Obsessive-Compulsive Spectrum Disorders. International Review of Psychiatry, 9, 99-109. http://dx.doi.org/10.1080/09540269775628

[2] Paula-Perez, I. (2013) Differential Diagnosis between Obsessive Compulsive Disorder and Restrictive and Repetitive Behavioural Patterns, Activities and Interests in Autism Spectrum Disorders. Revista de Psiquiatria y Salud Mental, 6, 178-186. http://dx.doi.org/10.1016/j.rpsmen.2012.07.006

[3] Van Ameringen, M., Patterson, B. and Simpson, W. (2014) DSM-5 Obsessive-Compulsive and Related Disorders: Clinical Implications of New Criteria. Depression and Anxiety, 31, 487-493. http://dx.doi.org/10.1002/da.22259

[4] Goodman, W.K. (2014) Obsessive Compulsive and Related Disorders. The Psychiatric Clinics of North America, 37, xi-xii. http://dx.doi.org/10.1016/j.psc.2014.06.005

[5] Ettelt, S., Ruhrmann, S., Barnow, S., Buthz, F., Hochrein, A., Meyer, K., et al. (2007) Impulsiveness in ObsessiveCompulsive Disorder: Results from a Family Study. Acta Psychiatrica Scandinavica, 115, 41-47. http://dx.doi.org/10.1111/j.1600-0447.2006.00835.x

[6] Sulkowski, M.L., Mancil, T.L., Jordan, C., Reid, A., Chakoff, E. and Storch, E.A. (2011) Validation of a Classification System of Obsessive-Compulsive Spectrum Disorder Symptoms in a Non-Clinical Sample. Psychiatry Research, 188, 65-70. http://dx.doi.org/10.1016/j.psychres.2011.01.015

[7] Phillips, K.A., Stein, D.J., Rauch, S.L., Hollander, E., Fallon, B.A., Barsky, A., et al. (2010) Should an Obsessive-Compulsive Spectrum Grouping of Disorders Be Included in DSM-V? Depression and Anxiety, 27, 528-555. http://dx.doi.org/10.1002/da.20705

[8] Keuthen, N.J., Osullivan, R.L., Ricciardi, J.N., Shera, D., Savage, C.R., Borgmann, A.S., et al. (1995) The Massachusetts General Hospital (MGH) Hairpulling Scale: 1. Development and Factor Analyses. Psychother Psychosom, 64, 141-145. http://dx.doi.org/10.1159/000289003

[9] Osullivan, R.L., Keuthen, N.J., Hayday, C.F., Ricciardi, J.N., Buttolph, M.L., Jenike, M.A., et al. (1995) The Massachusetts General Hospital (MGH) Hairpulling Scale: 2. Reliability and Validity. Psychother Psychosom, 64, 146-148. http://dx.doi.org/10.1159/000289004

[10] Rabiei, M., Nikfarjam, M., Khoramdel, K. and Movassagh, M.T. (2014) Factor Structure, Validity and Reliability of the Massachusetts General Hospital Hair Pulling Scale. Psychology and Behavioral Sciences, 3, 12-16. http://dx.doi.org/10.11648/j.pbs.20140301.13

[11] Tucker, B.T.P., Woods, D.W., Flessner, C.A., Franklin, S.A. and Franklin, M.E. (2011) The Skin Picking Impact Project: Phenomenology, Interference, and Treatment Utilization of Pathological Skin Picking in a Population-Based Sample. Journal of Anxiety Disorders, 25, 88-95. http://dx.doi.org/10.1016/j.janxdis.2010.08.007

[12] Keuthen, N.J., Wilhelm, S., Deckersbach, T., Engelhard, I.M., Forker, A.E., Baer, L., et al. (2001) The Skin Picking Scale-Scale Construction and Psychometric Analyses. Journal of Psychosomatic Research, 50, 337-341. http://dx.doi.org/10.1016/S0022-3999(01)00215-X

[13] Keuthen, N.J., Deckersbach, T., Wilhelm, S., Engelhard, I., Forker, A., O’Sullivan, R.L., et al. (2001) The Skin Picking Impact Scale (SPIS): Scale Development and Psychometric Analyses. Psychosomatics, 42, 397-403.

[14] Rabiei, M., Kalantari, M., Asgari, K. and Bahrami, F. (2014) Factor Structure, Validity and Reliability of the Revised Version of Skin Picking Scale. Zahedan Journal of Research in Medical Sciences, 16, 40-44.

[15] Phillips, K.A., Hollander, E., Rasmussen, S.A., Aronowitz, B.R., DeCaria, C. and Goodman, W.K. (1997) A Severity Rating Scale for Body Dysmorphic Disorder: Development, Reliability, and Validity of a Modified Version of the Yale-Brown Obsessive Compulsive Scale. Psychopharmacology Bulletin, 33, 17-22.

[16] Rabiei, M., Khormdel, K., Kalantari, K. and Molavi, H. (2010) Validity of the Yale-Brown Obsessive Compulsive Scale Modified for Body Dysmorphic Disorder (BDD) in Students of the University of Isfahan. Iranian Journal of Psychiatry and Clinical Psychology, 15, 343-350.

[17] Foa, E.B., Huppert, J.D., Leiberg, S., Langner, R., Kichic, R., Hajcak, G., et al. (2002) The Obsessive-Compulsive Inventory: Development and Validation of a Short Version. Psychological Assessment, 14, 485-496. http://dx.doi.org/10.1037/1040-3590.14.4.485

[18] Gignac, G.E., Palmer, B., Bates, T. and Stough, C. (2006) Differences in Confirmatory Factor Analysis Model CloseFit Index Estimates Obtained from AMOS 4.0 and AMOS 5.0 via Full Information Maximum Likelihood No Imputation: Corrections and Extension to Palmer et al. (2003). Australian Journal of Psychology, 58, 144-150. http://dx.doi.org/10.1080/00049530500504088

[19] Bartz, J.A. and Hollander, E. (2006) Is Obsessive-Compulsive Disorder an Anxiety Disorder? Progress in Neuro-Psychopharmacology and Biological Psychiatry, 30, 338-352. http://dx.doi.org/10.1016/j.pnpbp.2005.11.003

[20] Bienvenu, O.J., Samuels, J.F., Riddle, M.A., Hoehn-Saric, R., Liang, K.Y., Cullen, B.A., et al. (2000) The Relationship of 
Obsessive-Compulsive Disorder to Possible Spectrum Disorders: Results from a Family Study. Biological Psy- chiatry, 48, 287-293. http://dx.doi.org/10.1016/S0006-3223(00)00831-3

[21] Zohar, J. (2010) Addiction, Impulsivity and Obsessive-Compulsive Disorder: New Formulation Revealing Ancient Wisdom. The Israel Medical Association Journal, 12, 233.

[22] Potenza, M.N. (2007) Impulsivity and Compulsivity in Pathological Gambling and Obsessive-Compulsive Disorder. Revista Brasileira de Psiquiatria, 29, 105-106. http://dx.doi.org/10.1590/S1516-44462007000200004

[23] Stein, D.J., Hollander, E., Simeon, D. and Cohen, L. (1994) Impulsivity Scores in Patients with Obsessive-Compulsive Disorder. Journal of Nervous and Mental Disease, 182, 240-241. http://dx.doi.org/10.1097/00005053-199404000-00009 